\title{
IMPROVEMENTS IN ANTIBIOTIC PRESCRIBING BY COMMUNITY PAEDIATRICIANS IN THE CZECH RePUBLIC
}

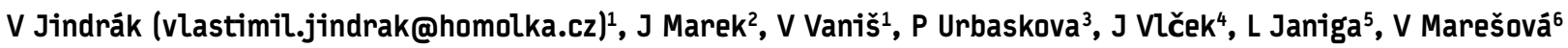 \\ 1. Antibiotic Centre, Na Homolce Hospital, Prague, Czech Republic \\ 2. Society for Primary Care Paediatricians, Czech Medical Association of J. E. Purkyně, Prague, Czech Republic \\ 3. National Reference Laboratory for Antibiotics, National Institute of Public Health, Prague, Czech Republic \\ 4. Department of Social and Clinical Pharmacy, Faculty of Pharmacy, Charles University, Hradec Králové, Czech Republic \\ 5. Janiga Labs Information Technology (IT) Company, Prague, Czech Republic \\ 6.1st Department of Infectious Diseases, 2nd Faculty of Medicine, Charles University, Prague, Czech Republic
}

Repeated surveys among primary care paediatricians were performed annually from 1998 to 2002 in the Czech Republic. The task was to assess the prescription of antibiotics in treatment of respiratory infections in children. The results were evaluated in the light of existing guidelines and conclusions were used in a number of interventions aimed at reducing the inadequate use of antibiotics and hence preventing the potential increase of the antibioticresistant bacteria. In addition, data on overall consumption of antibiotics in outpatient care and trends in the prevalence of resistant strains of Streptococcus pneumoniae and Streptococcus pyogenes are discussed.

\section{Introduction}

The centrally regulated healthcare system with limited financial resources, existing in the former communist Czechoslovakia, resulted in a low level of antibiotic consumption and rare occurrence of antimicrobial resistance. Despite the obvious defects of the system, some remarkable activities established during this period have proved beneficial from the long-term perspective. One of these was the establishment of "antibiotic centres" in the 1970s which contributed to promoting the prudent use of antibiotics. These organisational units were incorporated into the clinical microbiology departments and made responsible for local surveillance of antimicrobial resistance and supervision of the use of restricted antimicrobials. The network of antibiotic centres has remained active until the present time and currently represents a local structure ready to use for the organisation of systematic interventions.

A significant shift in antibiotic consumption was observed in the early 1990s, after the political changes. The most significant change was documented from 1992 to 1994 , when the privatisation of primary and outpatient care took place, and sophisticated marketing of pharmaceutical industry was introduced as a new phenomenon. In this period, the total ambulatory consumption of antibiotics increased from 14 to 20 defined daily doses (DDD) per 1,000 inhabitants and per day, and at the same time also the proportion of second-line antibiotics increased significantly although prescribing of these costly drugs was not appropriate in the existing epidemiological context [1]. The first warning signs of growing antimicrobial resistance among pathogens in the community were recorded a few years later. The earliest signal was associated with the rapidly increasing resistance of Streptococcus pyogenes to macrolides [2], which was probably due to changes in prescribing habits in primary paediatric care.

In these changed conditions, the application of new methods and innovative tools to prevent antibiotic resistance was needed. We describe a series of multicentre interventions, including annual surveys, aimed at identifying the diagnostic and prescribing habits and promoting the prudent use of antibiotics among participating paediatricians. In addition, we present data on overall ambulatory antibiotic consumption and antimicrobial resistance available from other sources.

\section{Methods}

\section{Survey of antibiotic prescriptions in paediatric care}

Annual surveys on outpatient antibiotic prescriptions in the treatment of respiratory infections in children were conducted among primary care paediatricians between 1998 and 2002. The surveys were organised every year during four weeks in November, with one week of follow up. The surveys in 1998, 1999 and 2000 were held in two Prague districts. The surveys in 2001 and 2002 were multicentre and involved 13 different districts across the Czech Republic. Participation in the survey was voluntary. Paediatricians were invited through regional coordinators of the Czech Society of Primary Care Paediatricians. Training sessions for participants were held before each annual survey: first centrally organised "training of trainers" later followed by local training seminars for participants in all regions. Two coordinators of the survey were established in every region including one expert from the antibiotic centre and one experienced paediatrician.

The questionnaire used in the survey focused on diagnostic and therapeutic approaches to the management of acute respiratory infections in children. The case definitions, criteria of appropriateness of antibiotic use and definitions of second-line antibiotics were adopted according to the national guidelines for antibiotic therapy in primary and ambulatory care issued, updated and disseminated by the Subcommittee on Antibiotic Policies of the Czech Medical Association [4]. Participating paediatricians were asked to fill in one questionnaire for each patient presenting with acute respiratory illness, irrespective of the prescription of antibiotics. Requested information included diagnostic approaches, 
such as indication of laboratory or other diagnostic tests (e.g. throat swab culture, C-reactive protein test, $\mathrm{X}$-ray examination). Aetiology of particular case of respiratory illness was presumed on the basis of clinical diagnosis. Computer software tools were developed for processing of questionnaires and validation and analysis of the data. The survey results were processed and communicated as individual, local and aggregated.

\section{Interventions, educational activities}

Feedback based on the results of the repeated surveys was the most important intervention tool used to promote good prescribing habits among participating doctors. This was accomplished by dissemination of printed survey results to individual doctors. In addition, a final conference and local seminars in regions were organised for participants to explain the obtained prescribing parameters. A comparison of individual approaches with a defined good practice was made.

Information obtained from the surveys was also used in educational activities organised by the Society for Primary Care Paediatricians, postgraduate training courses for all medical professionals and press conferences aimed at the general public.

\section{Surveillance of ambulatory antibiotic consumption}

We used data on ambulatory antibiotic consumption that is reported yearly to the European Surveillance of Antimicrobial Consumption (ESAC). It is calculated on the basis of information obtained from health insurance system. Data obtained from this source are processed by the national ESAC co-ordinator according to the methods agreed by the WHO Collaborating Centre for Drug Statistics Methodology and ESAC [3]. Only aggregated data on the overall ambulatory consumption of antibiotics are available. Detailed sorting of the data according to a geographical area or medical specialisation is not possible.

\section{Surveillance of antimicrobial resistance in community}

Monitoring of the resistance of bacterial pathogens causing respiratory infections in the community has been organised by the National Reference Laboratory for Antibiotics since 1996. About 50 antibiotic centres are involved in this periodic surveillance

F I G U R E 1

The proportion of antibiotic prescriptions in treatment of community-acquired respiratory tract infections in children, by clinical diagnosis. Output of multicentre survey of antibiotic use in primary paediatric care in the Czech Republic in 2001

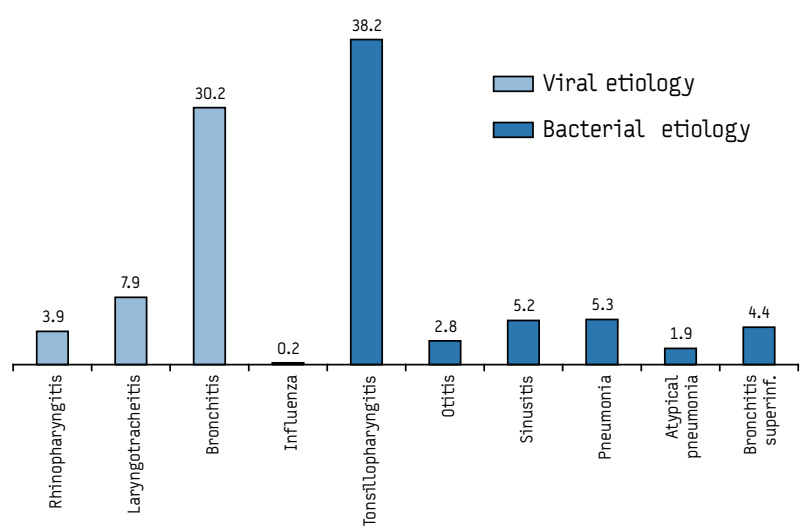

every year. It takes place during the last quarter of the year and in 2007 covered a catchment population of about $80 \%$. Every centre provides susceptibility data of 100 consecutive isolates of Streptococcus pneumoniae, Haemophilus influenzae and Streptococcus pyogenes from clinically relevant samples.

\section{Results}

\section{Survey of antibiotic prescriptions in paediatric care}

The repeated surveys identified the respiratory infections most frequently diagnosed as the cause of patients' visits to primary care paediatricians and revealed the doctors' prescribing habits in the context of particular clinical diagnosis $[5,6]$. The number of participating doctors varied from year to year: 13 took part in 1998, 23 in 1999, 28 in 2000, 114 in 2001 and 57 in 2002. The numbers of registered visits/cases of acute respiratory illnesses were the following: 3,707/3,006 (1999), 4,230/3,273 (2000), $31,077 / 19,013$ (2001), 14,801/9,373 (2002). The numbers of visits per practitioner were comparable.

In the first survey in 1998 only information on cases in which antibiotics were prescribed was collected. In the following surveys (1999-2002) all cases of acute respiratory infections were documented including those in which no antibiotics were administered.

Here we present the results of the largest and most representative multicentre survey performed in 2001, but similar output was obtained in other survey years as well. In the 2001 survey, 19,013 acute respiratory illness cases were registered by the participating paediatricians with the following clinical diagnoses: rhinopharyngitis $(56.3 \%$ of the cases), laryngotracheitis $(13.8 \%)$, bronchitis (16.8\%), influenza (1.9\%), tonsillopharyngitis (18.3\%), otitis $(2.2 \%)$, sinusitis $(2.4 \%)$, pneumonia $(1.9 \%)$, atypical pneumonia $(0.7 \%)$, bronchitis-bacterial superinfection (1.5\%). Several visits with different diagnoses could be linked to one case which is why the sum of these percentages exceeds $100 \%$. We estimated that in $42.2 \%$ of the cases in which antibiotics were prescribed, the prescriptions were issued inappropriately for an inadequate treatment of predominantly viral illnesses. Prescribing preferences according to clinical diagnosis are described in Figure 1 . Acute bronchitis and laryngotracheitis represented $38.1 \%$ of all indications for antibiotic treatment. This percentage indicates a large proportion of overuse and the opportunity for improvement. The treatment was initiated using second-line and more expensive drug in $47.2 \%$ of all cases in which antibiotics were prescribed while the first choice and mostly cheaper antibiotic recommended in an official guideline was not used.

\section{Interventions, educational activities}

Taking part in the survey and receiving feedback seems to have positively influenced the prescribing habits of participating physicians. The 57 doctors who participated in the survey in both 2001 and 2002 and reported a significant number of cases of acute bronchitis and laryngotracheitis, had changed their prescribing habits and considerably reduced the use of antibiotics in inadequate indications (Figure 2). A rapid improvement of prescribing preferences in the treatment of acute tonsillopharyngitis of 10 doctors participating in surveys in 1998, 1999 and 2000 is shown in Figure 3 as another example of the interventional effect.

Based on the results of the surveys, half-day seminars focused on prudent use of antibiotics in paediatrics were organised in all 
regions of the Czech Republic during 2002, in the framework of official educational activities of the Society for Primary Care Paediatricians. The information obtained from the surveys was disseminated via this multicentre educational event to all interested paediatricians. Easy to understand messages explaining the priorities for improvement and ways to reach better prescribing practices were communicated.

In addition, since 2002, interdisciplinary training courses on the use of antibiotics have been regularly organised by the Institute for Postgraduate Medical Education.

No specific financial resources were available for the preparation of systematic public campaigns. Nevertheless two press conferences specifically focused on the overuse of antibiotics and on the threat of antimicrobial resistance were held in 2002 and 2003.

\section{F I G U R E 2}

The proportion of antibiotic prescriptions in treatment of predominantly viral respiratory tract infections in children. Comparison of results of repeated surveys including 57 primary care paediatricians in the Czech Republic in 2001 and 2002

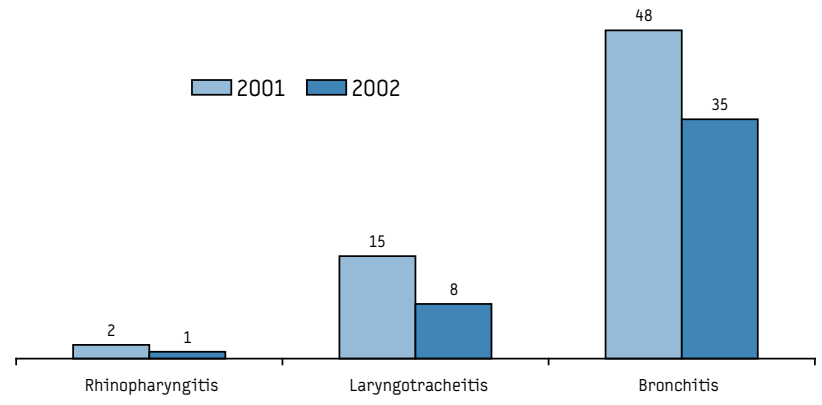

F I G U R E 4

Trends in ambulatory antibiotic consumption, Czech Republic, 1989 - 2007

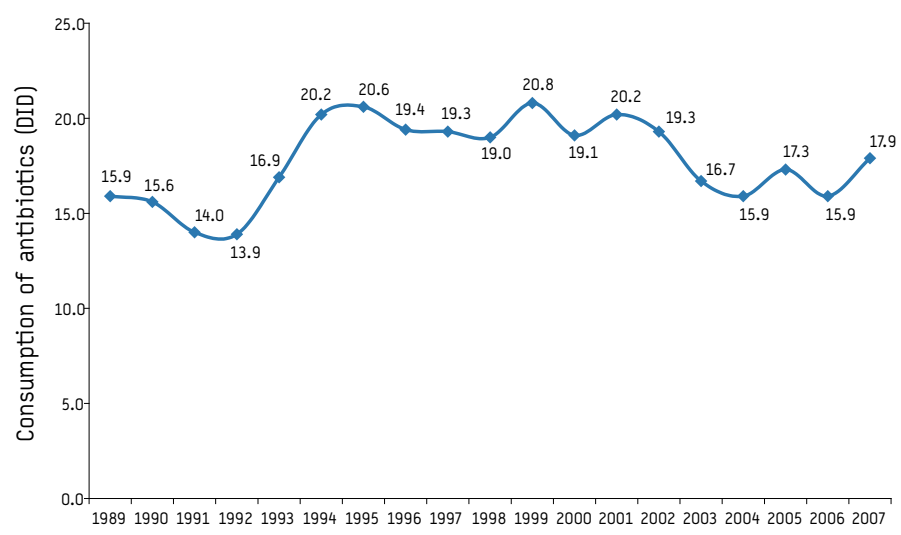

Year

Source of data: 1989-2002 [1], 2003-2006 [3], 2007 - preliminary data DID - Defined daily doses per 1,000 inhabitants and per day

\section{Trends in ambulatory antibiotic consumption}

The quantitative trends in outpatient consumption of antibiotics in the Czech Republic are shown in Figure 4. In the early 1990s, the total antibiotic consumption was approximately 14 DDD per 1,000 inhabitants and per day, with penicillins predominating. An increase of consumption to 20 DDD per 1,000 inhabitants and per day occurred during 1994, and remained at that level till 2002.

A qualitative change was observed from 1990 to 1994: the proportion of penicillins decreased giving way to macrolides (increase from 0.33 to 1.75 DDD per 1,000 inhabitants and per day), aminopenicillins with beta-lactamase inhibitors (0.01 to 1.4 DDD per 1,000 inhabitants and per day) and cephalosporines ( 0.16 to 1.04 DDD per 1,000 inhabitants and per day). Subsequently, in

F I G U R E 3

The proportion of various classes of antibiotics prescribed in treatment of acute tonsillopharyngitis in children. Comparison of results of repeated surveys including 10 primary care paediatricians, in the Czech Republic in 1998, 1999 and 2000

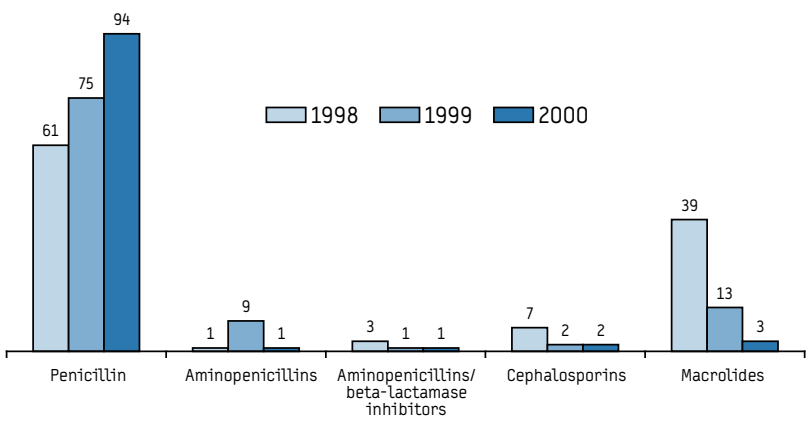

F I G U R E 5

Total consumption of macrolides in the community and resistance of Streptococcus pyogenes to erythromycin, Czech Republic, 1991-2007

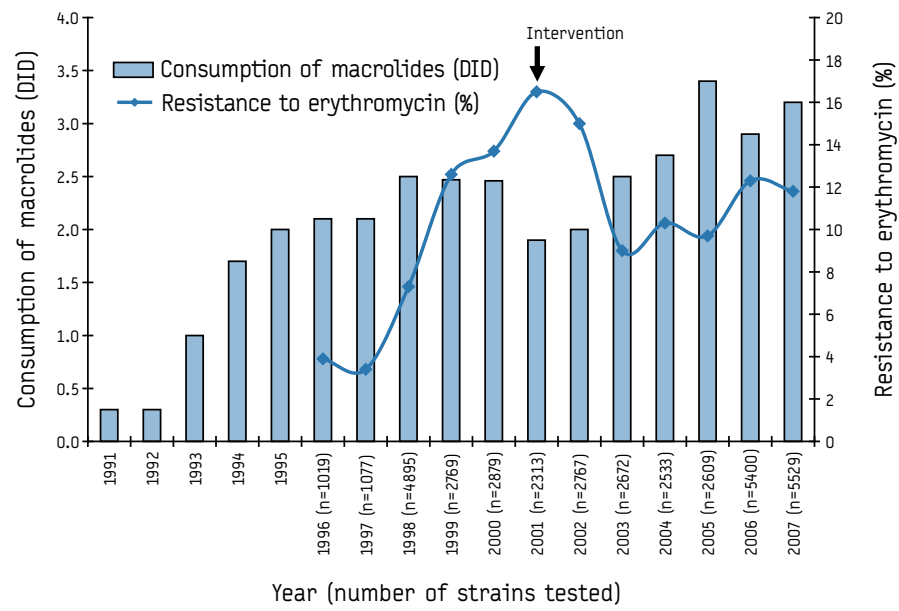

Note: The arrow indicates the beginning of official educational activities in prudent use of antibiotics in paediatric care organised by the Czech Medical Association

Source of data on consumption: 1989-2002 [1], 2003-2006 [3], $2007-$

preliminary data.

DID - Defined daily doses per 1,000 inhabitants and per day 
2003, a significant decrease of the overall antibiotic consumption was observed, however its qualitative structure remained inappropriate (high consumption of aminopenicillins with betalactamase inhibitors, macrolides and fluoroquinolones) $[1,3]$.

\section{Trends in antimicrobial resistance in community}

The resistance of some bacterial pathogens causing community acquired respiratory infections has remained low in the past years. This is namely true for Streptococcus pneumoniae. The strains causing invasive infections [7], as well as respiratory isolates are mostly fully susceptible to penicillin, intermediate susceptibility is present only in $4-5 \%$ of the isolates, and a high-level resistance is extremely rare. The resistance of invasive isolates to erythromycin is one of the lowest in Europe [7]. The situation is different for Streptococcus pyogenes. A rapid increase of resistance to erythromycin from 3\% to more than $16 \%$ was observed between 1996 and 2000. This dangerous trend was interrupted and the rates fell back to $9 \%$ in 2002-2003 [2]. A decrease in macrolide consumption during 2001-2002 was probably in the background of this phenomenon. However, from 2003, the consumption has been rapidly growing again, which is likely to cause increase in resistance.

\section{Discussion}

The fact that more than half of the patients' visits to paediatricians are due to common cold (56\% reported in 2001 survey) was surprising. At the same time, antibiotic prescription for common cold was rare. Nevertheless it is important to note that frequent visits due to this self-limited illness induce unnecessary overloading of paediatricians, when time and resources could be used to address more serious problems, including careful explanation of non-antibiotic management of viral illnesses to the patients and the parents.

In the surveys, the overuse of antibiotics for viral respiratory illnesses was especially marked in case of febrile, coughing children with diagnosis of acute bronchitis or laryngotracheitis. This clinical picture has a strong psychological impact influencing the decisions of doctors as well as treatment expectations of parents. Metaanalyses arguing in favour of non-antibiotic management of these diseases were available already during the 1990s but the traditional approach previously recommended antibiotic treatment.

The differentiation between bacterial and viral aetiology of acute tonsillopharyngitis and otitis media was not done in the surveys described here. However, an important fraction of these illnesses is caused by viruses and this fact represents another chance for improvement of diagnostics and antibiotic prescribing.

Our results clearly identified priorities for systematic interventions with a potential to eliminate about $40 \%$ of total antibiotic prescriptions in primary paediatric care. The influence of the repeated surveying showed good example of real improvement.

The limited availability of structured ambulatory consumption data makes it impossible to carry out a detailed analysis of antibiotic usage for particular medical specialities (primary care paediatricians, general practitioners for adults, outpatient specialists), for smaller geographical areas (regions, districts), and for the routine evaluation of prescribing patterns of individual doctors. Consequently, the impact of interventions is difficult to analyse, and the basis for routine performing of systematic activities are incomplete. This barrier seems to be an important obstacle in persuading health insurance companies to organise nationwide interventions.

No change in the healthcare reimbursement system was made which could have contributed to the decrease of antibiotic consumption observed from 2003. The change from "fee for service" to "per capita" payment was carried out for primary care in 1997, surprisingly without any influence on high ambulatory consumption of antibiotics during the late nineties. No significant differences in the occurrence of acute respiratory illnesses were observed in association with decreasing antibiotic consumption before or after 2003.

The decrease in the resistance of Streptococcus pyogenes to erythromycin seems to be in correlation with a time-limited decrease in macrolide consumption which may be at least partially attributed to the performed surveys and interventions (Figure 5). Nevertheless, more detailed analyses are needed to identify the reasons behind these resistance trends. Only a short interruption of the increasing macrolide consumption (2001-2002) indicates a limited sustainability of the outcome of performed interventions, which should be long lasting and nationwide. Otherwise, drug marketing can easily overcome its effectiveness.

The echo of press conferences has remained quite long lasting. There are more opportunities to address the general public in the media, including radio and television, in comparison with the previous period. The journalists seem to be still interested in this topic which facilitates the organisation of the first European Antibiotic Awareness Day this year.

\section{Conclusions and further developments}

The results of limited interventions performed in connection with the annual voluntary surveys among paediatricians in the Czech Republic provided good background for the planning of systematic nationwide activities focused on the prudent use of antibiotics and control of antimicrobial resistance in the community. The expectations regarding potential savings of the budget of the public health insurance system are fully justified. A specialised training of regional coordinators supporting good prescribing practice has been running since 2005 and a pool of competent professionals has been constantly growing. However, we are now at a starting point for further developments when routine operations of the existing know-how require regular support from the government and health insurance companies.

\section{Acknowledgements}

Authors are grateful to the Czech Society for Primary Care Pediatricians, Czech Medical Association J. E. Purkyně (personally to Hana Cabrnochová, president of Society), members of Subcommittee for Antibiotic Policy of the Czech Medical Association, local co-ordinators of survey project (namely Jana Henyšová, Zuzana Zemanová, Eliška Bébrová, Eva Šimečková, Magdaléna Horníková, Josef Scharfen, Eva Vítová, Helena Skačániová, Petr Ježek, Jana Kotalíková, Marie Zehnulová, Věra Tomášková, Pavel Adamec, Věra Hásková), all primary care paediatricians who participated in surveys, members of the Czech Working Group on Monitoring Antimicrobial Resistance, and the Czech Ministry of Health (for financial support of healthcare project "Improvement of quality of antibiotic usage aimed at controlling antimicrobial resistance" in 2003 and 2004). 


\section{References}

1. Dvořák P, Urbášková P, Štika L, Macková B, Bíba V. Používání antibiotik v ambulantní péči v České republice [The use of antibiotics in outpatient care in the Czech Republic] Prakt lék. 2004;84(7):369-374. [in Czech]

2. Urbášková P, Jakubů $V$, Pracovní skupina pro monitorování antibiotické rezistence (PSMR). Rezistence $k$ makrolidům $u$ druhu Streptococcus pyogenes $\checkmark$ České republice v období let 1996-2003 [Resistance to macrolides in the species Streptococcus pyogenes in the Czech Republic in 1996-2003]. Epidemiol Mikrobiol Imunol. 2004;53(4):196-202. [in Czech]

3. European Surveillance of Antimicrobial Consumption - ESAC. [homepage on the Internet]. Available from: http://www.esac.ua.ac.be

4. Česká lékařská společnost Jana Evangelisty Purkyně [Czech Medical Association J. E. Purkyně]. Léčebné standardy/Další odborné projekty [Therapeutical Standards/Other Expert Reports] [in Czech]. Available from: http://www.cls. cz/dalsi-odborne-projekty

5. Jindrák V, Henyšová J. Antibiotic prescribing in children with communityacquired respiratory tract infections in the situation of growing resistance to macrolides. European Congress of Clinical Microbiology and Infectious Diseases. Istanbul 2001. Abstract 0362.

6. Jindrák V. Hupková H. Antibiotic prescribing in the primary paediatric care in Central Eastern Europe - common history with different approaches. ESGAP official symposium. European Congress of Clinical Microbiology and Infectious Diseases. Prague 2004. Abstract: 10.1111/j.1198-743X.2004.902_s343.x.

7. European Antimicrobial Resistence Surveillance System - EARSS. EARSS Annual Report 2006. On-going surveillance of S. pneumoniae, S. aureus, E. coli, E. faecium, E. faecalis, K. pneumoniae, P. aeruginosa. Bilthoven, the Netherlands: EARSS Management Team; 2007. Available from: http://www.rivm.nl/earss/ Images/EARSS\%202006\%20Def_tcm61-44176.pdf

This article was published on 13 November 2008.

Citation style for this article: Jindrák V, Marek J, Vaniš V, Urbaskova P, Vlček J, Janiga , Marešová V. Improvements in antibiotic prescribing by community paediatricians in the Czech Republic. Euro Surveill. 2008;13(46):pii=19040. Available online: http:// www.eurosurveillance.org/ViewArticle.aspx?ArticleId=19040 